\title{
Improving Rheological Properties of Gambe Clay for Drilling Fluid Application Using Fermentable Polymers
}

\author{
A. O. Ibrahim*, O. R. Momoh, M. T. Isa \\ Department of Chemical Engineering, Ahmadu Bello University Zaria, Kaduna State, Nigeria.
}

\begin{abstract}
There are abundant bentonitic clay deposits in Nigeria. However, it does not meet commercial standard for drilling mud formulation, because it is composed of calcium montmorillonite. Therefore, there is need for the clay to be enhanced and polymers have been identified as enhancement agents. The work was aimed at improving the rheological properties of Gambe clay for drilling fluid formulation using the fermentable polymers (xanthan gum, locust bean gum and tamarind seed gum). The clay was obtained from Gambe town in Adamawa State, Nigeria. The clay was beneficiated for quartz removal and chemical beneficiated with $6 \mathrm{wt} \%$ of Na2CO3. The mineral composition and the cation exchange capacity of the clay was determined using X-ray diffraction analysis and ammonium acetate saturation method, respectively to find out its quality for drilling mud formulation. Drilling mud was formulated by mixing of $22.5 \mathrm{~g}$ of the clay to $350 \mathrm{ml}$ of water with a high speed mixer to obtain a homogenous mixture. The polymer enhancers were also added to the mixture. The effect of the fermentable polymer at different concentration on the rheological properties of the formulated drilling fluid was investigated employing FANN 35SA viscometer. It was found that $0.93 \mathrm{wt} \%$ of the tamarind seed gum, locust bean gum and xanthan gum in the formulated drilling fluid enhanced the yield point from $0.72 \mathrm{~Pa}$ to $7.2 \mathrm{~Pa}, 12.48 \mathrm{~Pa}$ and $16.36 \mathrm{~Pa}$, and the gel strength from $0 \mathrm{~Pa}$ to $8.35 \mathrm{~Pa}$, $10.44 \mathrm{~Pa}$ and $68.92 \mathrm{~Pa}$ of the formulated mud respectively. The mud enhanced with $0.80 \mathrm{wt} \%$ of the enhancers had high rheological properties than imported clay.
\end{abstract}

KEYWORDS: Drilling mud, Gambe clay, tamarind seed gum, locust bean gum, rheological properties.

[Received December 28, 2018; Revised May 13, 2018; Accepted June 23, 2018]

Print ISSN: 0189-9546 | Online ISSN: 2437-2110

\section{INTRODUCTION}

Drilling mud removes formation cuttings from beneath the bit and transports these cuttings to the surface. Drilling mud also prevents influx of formation fluids into the wellbore, maintains the stability of exposed formations, cools and lubricates the bit and drill string at points of contact with the cased or uncased borehole. It also helps to suspend the weight of the drill string and casing (Ukeles and Grinbaum, 2004). Hence, constructions of the oil and gas wells are very much influenced by the flow properties of the drilling mud used for the operations (Vipulanandan and Mohammed, 2014). The maximum shear stress that can be produced by the drilling mud is a very good indicator of its erodibility potential. Therefore, many additives are added to the clay used in drilling fluids formulations to modify viscosity, yield stress and maximum shear stress to improve drilling and also aid in the transfer of cuttings from the bottom of the well to the surface in addition to other functions (Kelessidis et al, 2013).

Bentonitic clays are required for the formulation of drilling fluid and are comprised of active ingredient such as smectite, montmorillonite, which have expandable 2:1 aluminosilicate mineral, having a three-layer plate-shaped crystalline structure. The colloidal system of bentonite has high non-Newtonian rheological properties and the suspending *Corresponding author's e-mail address: aoibrahim63@ gmail.com as well as shear-thinning characteristics desired in a drilling fluid (Ukeles and Grinbaum, 2004). However, there is need sometimes to modify the rheological properties of the clays to enhance their use in drilling fluid applications. Among the additives use for the modification of these rheological properties are polymers.

Polymer is made up of repeating chemical units known as monomers with relatively high molecular weight. Polymer could be used to modify water based bentonite drilling mud to improve viscosity, control fluid loss and minimize the interaction with the geological formations. Polymers can also be used as shear thinning agents to reduce viscosity when the mud is under relatively large shear strain rate. There are two broad types of water soluble polymers such as polysaccharides (biopolymers) and synthetic polymers (polyacrylamides).

The rheological models used for predicting the shear thinning behaviour of drilling mud are as follows.

Bingham plastic model is defined by the relationship in eqn (1).

$\tau=\tau_{o 1}+\mu_{p} \gamma$

where $\tau=$ shear stress, $\tau_{o 1}=$ yield stress $\mu_{p}=$ plastic viscosity and $\gamma=$ shear rate. 
A Bingham plastic fluid will not flow until the applied shear stress, $\tau$, exceeds the minimum value, $\tau$ _ol, known as the yield stress.

Herschel-Bulkley model defines a fluid with three parameters and can be represented mathematically as follows:

$\tau=\tau_{o 2}+k \gamma^{n}$

where $\tau, \tau_{o 2}, \gamma, k$ and $n$ represent the shear stress, yield stress, shear strain rate, correction parameter and flow behaviour index respectively.

The exponent $\mathrm{n}$ describes the shear thinning and shear thickening behaviour. Slurries are considered as shear thinning when $\mathrm{n}<1$ and shear thickening when $\mathrm{n}>1$. A fluid becomes shear thinning when the apparent viscosity decreases with the increase in shear strain rate (Vipulanandan and Mohammed, 2014).

Hyperbolic model also defines a fluid with three parameters and can be represented mathematically as follows:

$$
\tau-\tau_{o 3}=\frac{\dot{\gamma}}{A+D \dot{\gamma}}
$$

Dewu et al (2011) improved the rheological properties of local bentonite to meet commercial standard using polyanionic cellulose (PAC). Other researchers Olatunde et al (2012) attempted improving the rheological properties of local bentonite using guar gum, polyanionic cellulose and gum arabic but found out that gum arabic reached the commercial standard at very high concentration. Nevertheless, there is dearth of information on the use locust beam gum and tamarind gum. These materials could be alternative polymers for improving the properties of existing bentonitic clay. The raw materials for the development of drilling mud are also abundant in Nigeria, the bentonite deposits were estimated to be about 700 million tonnes located in the north-eastern Nigeria (Ahmed et al, 2012). However, the bentonites are still being imported into the country and it is expensive (Aghamelu and Okogbue, 2015).

This work is aimed at improving rheological properties of Gambe clay in the North-East Northern Nigeria using tamarind seed gum, locust beans gum and xanthan gum.

\section{MATERIALS AND METHODS \\ A. Collection and Preparation of Gambe Clay}

Sample of the clay was collected from Gambe, Mayo Belwa LGA, Adamawa State. It was sun dried for six hours, crushed and pulverized with a ball mill machine, and then sieved with $63 \mu \mathrm{m}$ mesh.

\section{B. Determination of the Mineral Composition of the Gambe Clay Sample}

The mineral composition was determined with X-ray diffractometer (XRD) (Empyrean Panalytical BV) at Nigerian Geological Survey Agency (NGSA) laboratory. The powdered sample was prepared for XRD analysis using the sample preparation block and compressed in the flat sample holder to create a flat smooth surface that was later mounted on the sample stage in the XRD cabinet. The sample was analysed using the reflection-transmission spinner stage, using the $\theta-\theta$ settings. $2 \theta$ starting position was 0.00483 and ends at 50.96483 with a $2 \theta$ step of 0.026 at 3.57 seconds per step. Tube current was set at $40 \mathrm{~mA}$ and a voltage of $45 \mathrm{kV}$.
The d-spacing of each peak was then obtained from Bragg equation for the appropriate value of $\lambda$. Once all $d$-spacing have been determined, automated search/match routines of the d-spacing of the unknown were compared with those of the standards. The diffractograms were processed and displayed automatically using attached computer system.

\section{Particle Size Distribution Analysis}

The pipette method was used to determine the particle size distribution of the clay. The powdered clay sample was sieved to obtain $63 \mu \mathrm{m}$ size which is the required specification for this analysis. Exactly $125 \mathrm{ml}$ of $40 \mathrm{~g} / \mathrm{L}$ sodium hexametaphosphate was added to $25 \mathrm{~g}$ of the clay sample in $250 \mathrm{ml}$ beaker and thoroughly mixed using a glass stirring rod and allowed to stand overnight. The beaker was gently agitated on a shake table for 3 hours and its content was then transferred into a 1 litre measuring cylinder, distilled water was then added to the cylinder to the 1 litre mark.

Seven clean $50 \mathrm{~mL}$ beakers were rinsed with distilled water and dried in an oven at $50^{\circ} \mathrm{C}$ for an hour. Each beaker was weighed on an analytical balance, recording each weight alongside each beaker number. The clay solution was vigorously agitated in the $1000 \mathrm{ml}$ graduated cylinder using a stirring rod. The settling time was evaluated using Stoke's principle after which samples were withdrawn with a pipette of $20 \mathrm{ml}$ from the depths indicated at each settling time. Afterwards the beakers were covered and placed into a drying oven. The samples were dried for 24 hours at $70^{\circ} \mathrm{C}$. After the drawn samples had dried, they were removed from the oven and allowed to cool at room temperature. Each beaker was weighed and the sample mass was determined by subtracting the weight of the beaker.

\section{Determination of Cation Exchange Capacity (CEC)}

Ammonium acetate saturation method was used to determine CEC of the clay sample (Caenn et al, 2011). Ten grams air dried Gambe clay was weighed into $500 \mathrm{ml}$ Erlenmeyer flask and $40 \mathrm{ml}$ of one normality (1 N) ammonium acetate was added and shaken thoroughly then allowed to stand for 24 hours. The clay was filtered using plastic funnel fitted with No 1 filter paper. The clay was further leached four times with neutral one normality $(1 \mathrm{~N})$ ammonium chloride and once with $0.25 \mathrm{~N}$ ammonium chloride. The electrolyte was washed with $200 \mathrm{~mL} 99 \%$ ethanol and washed again with 1 one normality $(1 \mathrm{~N})$ sodium chloride. The clay and the filtrate were then transferred into $500 \mathrm{ml}$ flask containing $200 \mathrm{~mL}$ of distilled water, then four drops of liquid paraffin and $10 \mathrm{ml}$ of one normality $(1 \mathrm{~N}) \mathrm{NaOH}$ were added to prevent fuming.

$60 \mathrm{ml}$ of the solution was distilled into $50 \mathrm{ml}$ of $2 \%$ boric acid solution measured into $250 \mathrm{ml}$ Erlenmeyer flask. Drops of mixed indicator were added and the ammonium-borate produced was titrated with standard $0.02 \mathrm{~N} \mathrm{H}_{2} \mathrm{SO}_{4}$ to get the colour changed from bluish-green to pink at the end point. The milliequivalent of ammonium in $100 \mathrm{~g}$ of clay was calculated using eqn (4).

$$
\begin{aligned}
& E C(\text { meq } / 100 g)=\frac{(T-B) \times N \times 100}{W} \\
& \text { where: } \\
& \mathrm{T}=\text { Volume of acid used in the titration } \\
& \mathrm{B}=\text { Titre value for blank }
\end{aligned}
$$


$\mathrm{N}$ = Normality of acid used

$\mathrm{W}=$ weight of clay used.

\section{E. Chemical Beneficiation of the Gambe Clay}

One hundred grams of the clay was dispersed in $150 \mathrm{~mL}$ of $6 \mathrm{~g} / \mathrm{L} \mathrm{Na}{ }_{2} \mathrm{CO}_{2}$ solution and then $50 \mathrm{~mL}$ of distilled water was added and stirred for 5 minutes. It was left for 24 hours for proper ion exchange. This was to obtain base clay which has far better swelling capacity than the predominantly abundant calcium clay in the region. The paste was then oven dried at 70 ${ }^{\circ} \mathrm{C}$ for 24 hours and ground for particle size reduction and sieved to $63 \mu \mathrm{m}$.

\section{F. Drilling Mud Formulation}

Drilling mud was formulated by mixing of $22.5 \mathrm{~g}$ of the clay to $350 \mathrm{ml}$ of water with a high speed mixer at $18000 \mathrm{rpm}$ for $60 \mathrm{~s}$ to obtain a homogenous mixture. The tamarind seed gum of $0.5 \mathrm{~g}$ was also added to the mixture and then mixed at $18000 \mathrm{rpm}$ for $40 \mathrm{~s}$. The mud formed was allowed to hydrate for 24 hours. Similar procedure was done for other formulation of weight of polymer ranging from $0.5 \mathrm{~g}$ to $3.5 \mathrm{~g}$ as shown in Table 1.

Table 1: Concentration of polymer for drilling mud formulation

\begin{tabular}{llllllll}
\hline $\begin{array}{l}\text { Mass of polymer } \\
(\mathbf{g})\end{array}$ & $\mathbf{0 . 5}$ & $\mathbf{1 . 0}$ & $\mathbf{1 . 5}$ & $\mathbf{2 . 0}$ & $\mathbf{2 . 5}$ & $\mathbf{3 . 0}$ & 3.5 \\
\hline $\begin{array}{l}\text { Concentration of } \\
\text { the polymer in } \\
\text { the formulated } \\
\text { drilling fluid (wt } \\
\%)\end{array}$ & 0.13 & 0.27 & 0.40 & 0.53 & 0.67 & 0.80 & 0.93 \\
\hline
\end{tabular}

\section{G. Determination of Rheological Properties}

FANN 35SA viscometer was used to determine the rheological properties. The design includes R1 Rotor Sleeve, B1 Bob, F1 Torsion Spring, and a stainless steel sample cup for testing according to American Petroleum Institute (API) recommended practice for field testing water based drilling fluids.

The mud sample was mixed at $18000 \mathrm{rpm}$ with a mixer until a homogeneous mixture was obtained, while avoiding formation of foam. The sample was then poured into heat cup (sample holder) and mounted to position. The base was lifted until the level of fluid met the scribed line on the rotor sleeve and the lock screw was tightened.

The Model 35SA viscometers operate at six speeds, which are 5.1, 10.2, 170.7, 341.3, 512 and $1024 \mathrm{~s}-1$. To select the 5.1 $\mathrm{s}-1$, the speed switch (located on the right side of the base) was set to low speed position. Then the motor was turned on and moved the gear shift knob (located on the top of the instrument) to the centre. The $3 \mathrm{rpm}$ reading was recorded when the indicator dial gauge value was steady. Similar procedure was done for 10.2, 170.7, 341.3, 512 and $1024 \mathrm{~s}-1$. The plastic viscosity (PV) and yield point (YP) were determined using eqns (5) and (6).

$$
P V=\begin{gathered}
\text { Dial reading at } 600 \mathrm{rpm}- \\
\text { dial reading at } 300 \mathrm{rpm}\} \times 10^{-3} \quad(\text { Pa.s })
\end{gathered}
$$

$$
Y P=\{\text { Dial reading at } 300 \mathrm{rpm}-\mathrm{PV}\} \times 0.479(\mathrm{~Pa})
$$

\section{H. Determination of Gel Strength of the Drilling Fluid}

The FANN 35SA viscometer was used to determine the gel strength of the mud at $10 \mathrm{~s}$ and $10 \mathrm{~min}$. The formulated mud was poured into heat cup and mounted to position. The base was lifted until the level of fluid met the scribed line on the rotor sleeve and the lock screw was tightened. The sample was stirred at $600 \mathrm{rpm}$ for $15 \mathrm{~s}$ and the gear assembly was lifted to the neutral (centre) position. The motor was shut off and waited for $10 \mathrm{~s}$. The switch to the low-speed position was flipped and maximum deflection was recorded in $\mathrm{Pa}$ as 10 -s gel. The same procedure used to determine the gel strength at $10 \mathrm{~s}$ was repeated for $10 \mathrm{~min}$ to obtain the 10 -min gel.

\section{Fitting of Rheological Models for the Gambe Drilling Mud}

In this study, the measured shear stress and shear rate were fitted to the three rheological models using commercial mathematical software, MATLAB® version 8.4. The models were fitted to the experimental data using lsqcurvefit solver. The lsqcurvefit solves nonlinear curve-fitting problems in least-squares sense. In addition, coefficient of determination (R2) and the root mean square error (RMSE) in curve fitting were also calculated.

\section{RESULTS AND DISCUSSION}

\section{A. Mineral Composition of the Gambe Clay}

Figure 1 shows the XRD result of raw Gambe clay. From the figure, the XRD patterns show the presence of $\mathrm{Ca}$ montmorillonite $\left[\mathrm{Ca}_{0.2}(\mathrm{Al}, \mathrm{Mg}) 2 \mathrm{Si}_{4} \mathrm{O}_{10}(\mathrm{OH})_{2} .4 \mathrm{H}_{2} \mathrm{O}\right]$ at Bragg angle of $5.8^{\circ}$ and $17.6^{\circ}$ which implies that the clay has shear-thinning characteristics.

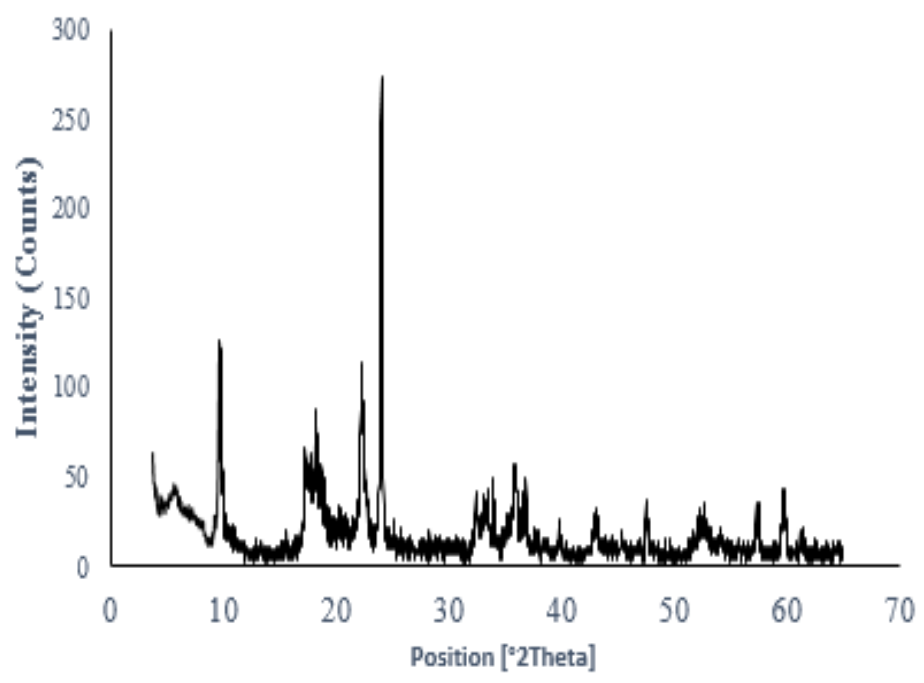

Figure 1: XRD patterns for raw Gambe clay. 


\section{B. Particle Size Distribution Analysis}

Table 2 shows the particle size distribution of Gambe clay using pipette method. The particle size of montmorillonite may be as large as $2 \mu \mathrm{m}$ and as small as $0.2 \mu \mathrm{m}$ (Otterstedt and Brandreth, 1998). From Table 2, the percentage of montmorillonite present in the clay was found to be $9.63 \%$ which was lower than that of El-Fayoum clay of $89.6 \%$ (ElMahllawy et al, 2013).

Table 2: Particle size Distribution of Raw Gambe Clay.

\begin{tabular}{cccccccc}
\hline $\begin{array}{c}\text { Range of } \\
\text { particle } \\
\text { size } \\
(\boldsymbol{\mu m})\end{array}$ & $\begin{array}{c}63- \\
62.5\end{array}$ & $\begin{array}{c}62.5- \\
31\end{array}$ & $\begin{array}{c}31- \\
16\end{array}$ & $\begin{array}{c}16- \\
8\end{array}$ & $8-4$ & $4-2$ & $\begin{array}{c}2- \\
0.5\end{array}$ \\
\hline wt. \% & 25.14 & 22.57 & 19.17 & 6.59 & 10.1 & 6.8 & 9.63 \\
\hline
\end{tabular}

Table 3 shows the cation exchange capacity of the clay samples using ammonium acetate saturation method. The CEC reveals the molar charge of exchangeable ions which is of importance for the swelling characteristics of montmorillonite (Ceann et al, 2011). As shown in Table 3, the cation exchange capacity of raw Gambe clay increased from about 32 to 39 meq/100g after beneficiation which was lower than commercial standard of $83.2 \mathrm{meq} / 100 \mathrm{~g}$. These low values would result in drilling mud with low rheological properties (Shuwa, 2010).

Table 3: Cation Exchange Capacity of the Clay Samples.

\begin{tabular}{lccc}
\hline & $\begin{array}{l}\text { Raw Gambe } \\
\text { clay }\end{array}$ & $\begin{array}{l}\text { Beneficiated } \\
\text { Gambe clay }\end{array}$ & Commercial clay \\
\hline $\begin{array}{l}\text { CEC } \\
(\mathrm{meq} / 100 \mathrm{~g})\end{array}$ & 32.2 & 38.7 & 83.2 \\
\hline
\end{tabular}

\section{Flow Properties of the Formulated Mud}

The shear stress at shear rate of 1024 s-1 of the raw Gambe clay mud was found to be $2.04 \mathrm{~Pa}$ which slightly increased to $2.30 \mathrm{~Pa}$ after beneficiation which was lower than commercial standard of $15.32 \mathrm{~Pa}$ as indicated in Figure 2. This is in agreement with James et al (2008).

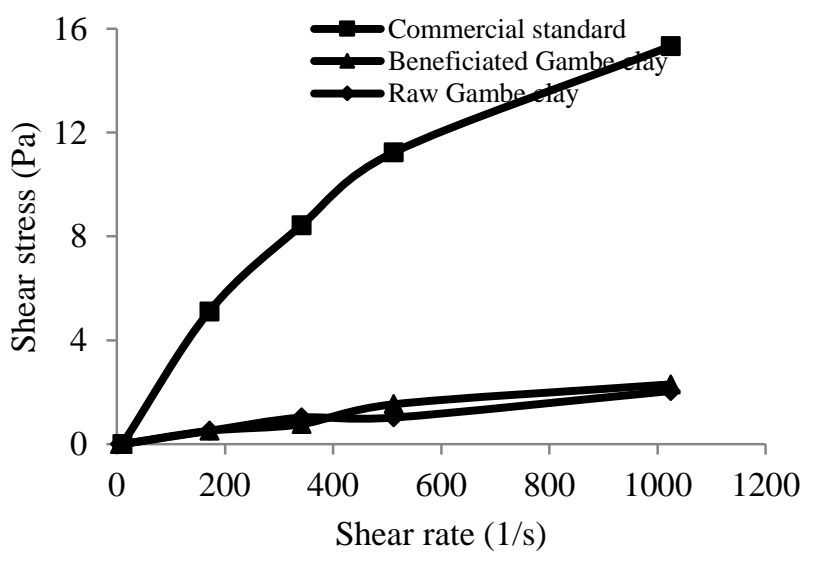

Figure 2: Flow behaviour of Gambe clay mud.

Figure 3 shows the beneficiated drilling mud treated with 0.93 wt $\%$ tamarind seed gum, which raised shear stress at shear rate at $1024 \mathrm{~s}-1$ from $2.30 \mathrm{~Pa}$ to $29.00 \mathrm{~Pa}$ which is about $940 \%$ higher. As shown in the figure, to obtain flow property close to commercial standard, the clay should be treated with 0.80 wt $\%$ tamarind seed gum. The polymers in the bentonite suspension interact with clay particles according to their nonionic character. The polymers were adsorbed on the surface of clay minerals by steric interactions (El-Mahllawy et al, 2013).

The formulated mud with tamarind seed gum was found to have viscometer dial reading at $600 \mathrm{rpm}$ lower than that of the mud formulated using guar gum by $55.3 \%$ prepared in the work of Olatunde et al (2012). This difference could probably be due to difference in average molecular weight where guar gum has average molecular weight ranging from 1,000,000 $\mathrm{g} / \mathrm{mol}$ to 2,000,000 $\mathrm{g} / \mathrm{mol}$ (Mathur, 2012) which is higher than that of tamarind seed gum ranging from $50,000 \mathrm{~g} / \mathrm{mol}$ to $115,000 \mathrm{~g} / \mathrm{mol}$ (Wüstenberg, 2015).

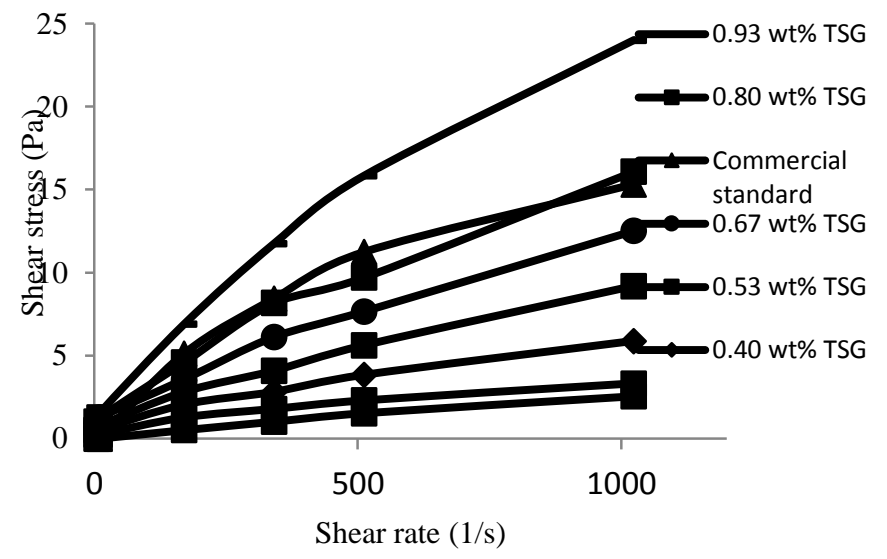

Figure 3: Flow behaviour of Gambe clay treated with tamarind seed gum.

Figure 4 shows the beneficiated drilling mud treated with $0.93 \mathrm{wt} \%$ of locust bean gum, which raised the shear stress at shear rate of $1024 \mathrm{~s}-1$ from $2.30 \mathrm{~Pa}$ to $32.68 \mathrm{~Pa}$ (about $1320 \%$ higher). This value was higher than its equivalent value when tamarind seed gum was used because it had higher average molecular weight (ranging from 300,000-2,000,000 g/mol) (Biliaderis and Izydorczyk, 2007).

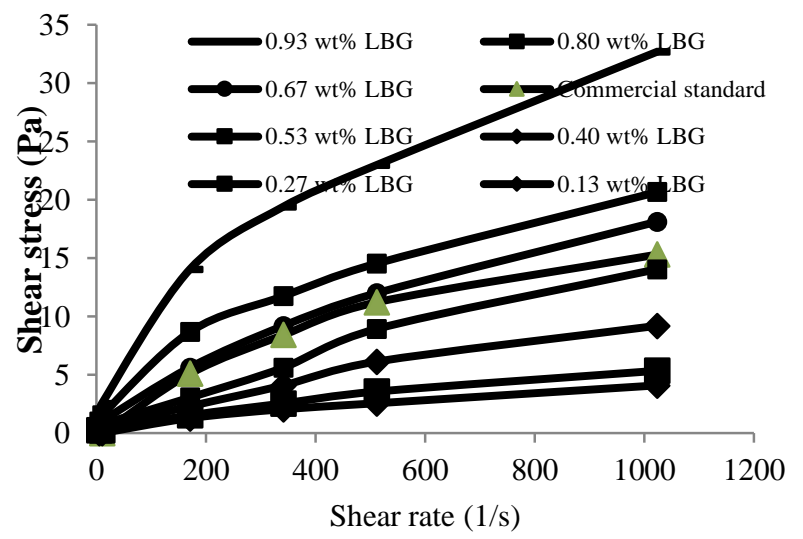

Figure 4: Flow behaviour of Gambe clay treated with locust bean gum.

As shown in the figure, to obtain flow property close to commercial standard, the clay should be treated with $0.67 \mathrm{wt} \%$ 
locust bean gum. The formulated mud with locust bean gum was found to have viscometer dial reading at $600 \mathrm{rpm}$ lower than that of the mud formulated using guar gum by $14.1 \%$ (Olatunde et al, 2012). This difference could probably be due to locust bean gum having substantially fewer D-galactosyl sidegroups than guar gum (Maier et al, 2013).

Figure 5 shows the beneficiated drilling mud treated with $0.93 \mathrm{wt} \%$ xanthan gum raised the shear stress at shear rate at $1024 \mathrm{~s}-1$ from $2.30 \mathrm{~Pa}$ to $32.68 \mathrm{~Pa}$ which is about $1320 \%$ higher. To obtain flow property close to commercial standard, the clay should be treated with $0.40 \mathrm{wt} \%$ xanthan gum. Therefore, xanthan gum improved the clay property better than both locust bean gum and tamarind seed gum because of its high average molecular weight (> 2,000,000 $\mathrm{g} / \mathrm{mol}$ ) (Wüstenberg, 2015).

The formulated mud with xanthan gum was found to have viscometer dial reading at $600 \mathrm{rpm}$ lower than that of the mud formulated using guar gum by $14.1 \%$ as reported by Olatunde et al (2012) even though xanthan gum has higher average molecular weight than guar gum. This difference could be due to presence of calcium ions (from the XRD result) in the mud which causes poor yield of the xanthan gum at high $\mathrm{pH}$ (Ukeles and Grinbaum, 2004)

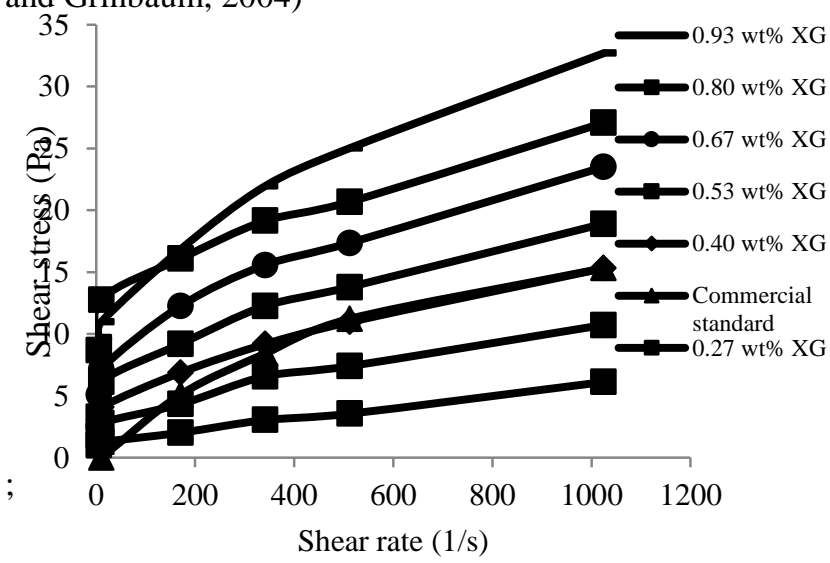

Figure 5: Flow behaviour of Gambe clay treated with xanthan gum.

Figure 6 shows variation of plastic viscosity of the mud with the concentration of the polymers. It could be found that tamarind seed gum, locust bean gum and xanthan gum enhanced the plastic viscosity of the formulated mud from 0.0015 Pa.s to 0.016, 0.019 and 0.015 Pa.s, respectively which was higher than commercial standard of 0.008 Pa.s. The formulated mud with these polymers was found to have lower plastic viscosity than the formulated mud with carboxy methylcellulose (CMC) as reported by Ibrahim et al, 2017.

Figure 7 shows variation of yield point of the mud with the polymers. It was found that xanthan gum had the highest yield point and tamarind seed gum had the least yield point. The results further showed that tamarind seed gum, locust bean gum and xanthan gum enhanced the yield point of the formulated mud from $0.72 \mathrm{~Pa}$ to $12.45 \mathrm{~Pa} 7.18 \mathrm{~Pa}$ and 16.29 $\mathrm{Pa}$ respectively. Each of these values was higher than commercial standard of $6.71 \mathrm{~Pa}$ and the formulated mud with polyanionic cellulose as reported by Dewu et al (2011). Only the formulated mud with xanthan gum had higher yield point than formulated mud with CMC as reported by Ibrahim et al (2017).

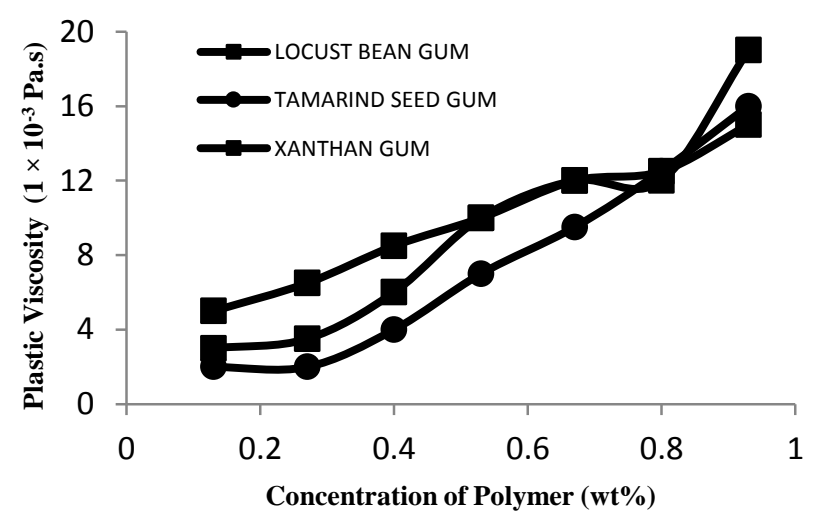

Figure 6: Variation of plastic viscosity of the mud with the polymers.

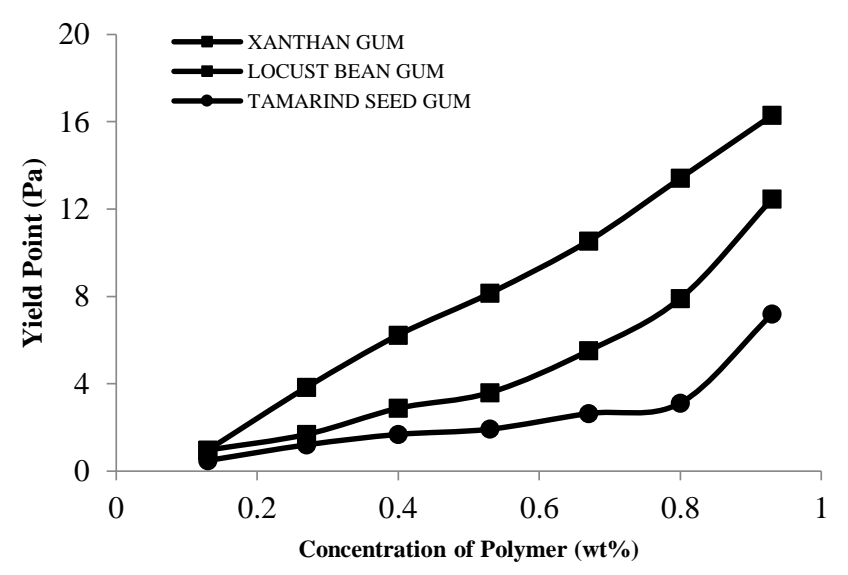

Figure 7: Variation of yield point of the mud with the polymers.

\section{Gel Strength of the Treated Gambe Clay Mud}

Figures 8 and 9 show variation of the gel strength at 10seconds and 10-minutes respectively of the mud with the polymers. It could be found that xanthan had the highest gel strength and tamarind seed gum had the least gel strength ratio. To obtain property of gel strength at 10 seconds close to commercial standard, the clay is to be treated with either 0.93 wt $\%$ locust bean gum or $0.27 \mathrm{wt} \%$ xanthan gum whereas to obtain property of gel strength at 10 minutes close to commercial standard, the clay is to be treated with $0.40 \mathrm{wt} \%$ xanthan gum. Only the formulated mud with xanthan gum and locust bean gum had higher gel strength than formulated mud with CMC as reported by Ibrahim et al (2017). 


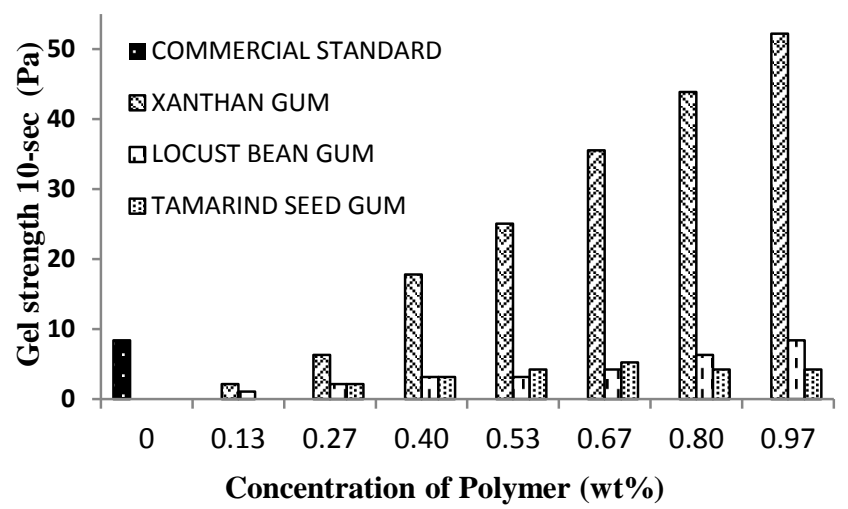

Figure 8: Variation of Gel strength at 10-sec of the mud with the polymers.

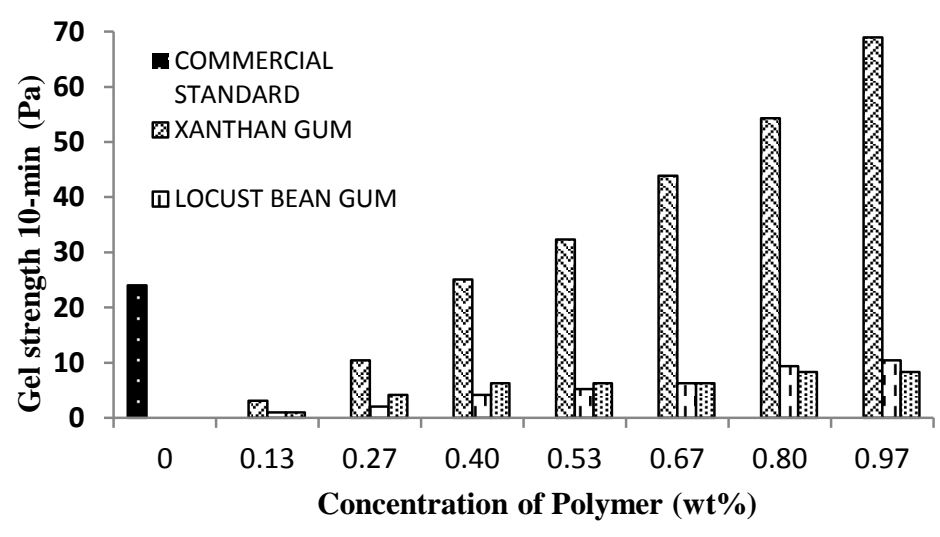

Figure 9: Variation of Gel strength at 10-min of the mud with the polymers.

\section{E. Fitting of Rheological Models for Gambe Clay Drilling Mud}

Table 4 presents rheological parameters of Gambe clay mud treated with polymers. Though the beneficiated Gambe clay mud did not meet commercial standard but it satisfied the shear thinning conditions $(\mathrm{n}<1)$ which implies that the mud is a pseudoplastic fluid. The best model that fitted rheological data was hyperbolic model based on the coefficient of determination (R2) and root mean square of error (RMSE).

It was found that these formulated mud treated with tamarind seed gum satisfied the shear thinning conditions. The best model that fitted the formulated mud at concentration of $0.80 \mathrm{wt} \%$ and $0.93 \mathrm{wt} \%$ tamarind seed gum were HerschelBulkley and hyperbolic models respectively. It also met commercial standard at this concentration.

It was found that these formulated mud treated with locust bean gum satisfied the shear thinning conditions. The best model that fitted the formulated mud at concentration of $0.80 \mathrm{wt} \%$ and $0.93 \mathrm{wt} \%$ locust bean gum were Herschel-Bulkley model. They also met commercial standard at these concentrations.

It was found that these formulated mud treated with xanthan gum satisfied the shear thinning conditions. The best model that fitted that the formulated mud (at concentration of $0.40 \mathrm{wt} \%, 0.53 \mathrm{wt} \%, 0.67 \mathrm{wt} \%, 0.80 \mathrm{wt} \%$ and $0.93 \mathrm{wt} \%$ xanthan gum) was Herschel-Bulkley model. They also met commercial standard.

\section{CONCLUSIONS}

In this study, the Gambe clay was beneficiated with $6 \mathrm{wt} \%$ $\mathrm{Na}_{2} \mathrm{CO}_{2}$ and rheological properties including yield point, plastic viscosity and gel strength of formulated mud enhanced with tamarind seed gum, locust bean gum and xanthan gum was investigated. Based on X-ray diffraction (XRD) analyses the clay had montmorillonite. The cation exchange capacity of raw Gambe clay increased from 32 to 39 meq/100g after beneficiation which was lower than commercial standard of $83.2 \mathrm{meq} / 100 \mathrm{~g}$.

The following conclusions can be drawn from the research:

- The shear stress at shear rate of 1024 s-1 of the beneficiated Gambe clay mud was found to be $2.30 \mathrm{~Pa}$ which was lower than commercial standard of 15.32 Pa.

- Treatment of Gambe clay with tamarind seed gum, locust bean gum and xanthan gum resulted to high value of rheological properties. The mud enhanced with $0.80 \mathrm{wt} \%$ of the enhancers had high rheological properties than imported clay (Wyoming clay).

- Herschel-Bulkley model gave a good fit for xanthan gum and locust bean gum treated mud while hyperbolic model gave a good fit for tamarind seed gum treated muds based on the coefficient of determination and root mean square of error.

\section{REFERENCES}

Aghamelu, O. P. and Okogbue, C. O. (2015). Characterization of some clays from Nigeria for their use in drilling mud. Applied Clay Science, 116: 158-166.

Ahmed, A. S.; N, Salahudeen, C. S. Ajinomoh, and A. Ohikere, (2012). Studies on the mineral and characteristics of Pindiga bentonitic clay. Petroleum Technology Development Journal, 1: 1-8.

Biliaderis, C. G. and Izydorczyk, M. S. (2007). Functional food carbohydrates. CRC Press, Boca Raton.

Caenn, R., Darley, H. and Gray, G. (2011). Composition and Properties of Drilling and Completion Fluids (6th ed.). Elsevier Inc, Oxford.

Dewu, B. B. M.; S. A., Arabi, M. O. A., Oladipo, I. I., Funtua, I. A., Mohammed-Dabo, and A. M. Muhammad. (2011). Improvement of rheological properties of bentonitic clays using sodium carbonate and synthetic viscosifiers. International archive of applied science and technology, 2(2): 43-52.

El-Mahllawy, M. S.; A. M., Sharara, M. M. Hassaan, and A. M. Abdel Haleem (2013). The composition and activation aspects of El-Fayoum clays for using as a drilling fluid. Egyptian Journal of Petroleum. 22: 395-404

Ibrahim, A. O.; O. R. Momoh, and M. T. Isa (2017). Enhancement of Gambe clay using un-fermentable polymers for drilling mud formulation. Nigerian Journal of Technology, 36(1): 119 - 126 . 
Table 4: Bingham Plastic, Herschel-Bulkley and Hyperbolic Models Parameter for Gambe Clay Mud Treated the Polymers.

\begin{tabular}{|c|c|c|c|c|c|c|c|c|c|c|c|c|c|c|}
\hline \multirow{2}{*}{$\begin{array}{c}\text { Polymer } \\
(\%)\end{array}$} & \multicolumn{3}{|c|}{ Bingham Plastic Model Eq. } & \multirow[b]{2}{*}{ RMSE } & \multicolumn{4}{|c|}{ Herschel-Bulkley Model Eq. } & \multirow[b]{2}{*}{ RSME } & \multicolumn{2}{|c|}{ Hyperbolic Model Eq } & \multirow[b]{2}{*}{$\begin{array}{c}D \\
(\mathbf{P a})^{-1}\end{array}$} & \multirow[b]{2}{*}{$\mathbf{R}^{2}$} & \multirow[b]{2}{*}{ RSME } \\
\hline & $\begin{array}{l}\tau_{o 1} \\
(\mathbf{P a})\end{array}$ & $\begin{array}{c}\mu_{p} \\
\text { (Pa.s) }\end{array}$ & $\mathbf{R}^{2}$ & & $\begin{array}{c}\tau_{o 2} \\
(\mathbf{P a})\end{array}$ & $\begin{array}{c}k \\
(\text { Pa.sn })\end{array}$ & $n$ & $\mathbf{R}^{2}$ & & $\begin{array}{c}\tau_{o 3} \\
(\mathbf{P a})\end{array}$ & $\begin{array}{c}A \\
(\text { Pa.s. })^{-1}\end{array}$ & & & \\
\hline \multicolumn{15}{|c|}{ Commercial standard (Wyoming clay mud) } \\
\hline 0.00 & 1.92 & 0.015 & 0.934 & 1.469 & 0.00 & 0.259 & 0.59 & 0.994 & 0.440 & 0.48 & 28.1 & 0.040 & 0.998 & 0.267 \\
\hline \multicolumn{15}{|c|}{ Beneficiated Gambe clay mиd } \\
\hline 0.00 & 0.05 & 0.002 & 0.97 & 0.175 & 0.00 & 0.007 & 0.84 & 0.980 & 0.143 & 0.00 & 318 & 0.119 & 0.983 & 0.132 \\
\hline \multicolumn{15}{|c|}{ Gambe clay mud treated with tamarind seed gum } \\
\hline 0.13 & 0.06 & 0.002 & 0.987 & 0.125 & 0.00 & 0.008 & 0.84 & 0.997 & 0.064 & 0.00 & 291 & 0.105 & 0.998 & 0.046 \\
\hline 0.27 & 0.50 & 0.003 & 0.942 & 0.322 & 0.05 & 0.069 & 0.56 & 0.999 & 0.043 & 0.22 & 150 & 0.179 & 0.996 & 0.078 \\
\hline 0.40 & 0.70 & 0.005 & 0.965 & 0.445 & 0.15 & 0.065 & 0.65 & 0.998 & 0.122 & 0.35 & 103 & 0.081 & 0.992 & 0.188 \\
\hline 0.53 & 0.94 & 0.008 & 0.985 & 0.453 & 0.44 & 0.045 & 0.76 & 0.999 & 0.129 & 0.60 & 81.7 & 0.037 & 0.998 & 0.201 \\
\hline 0.67 & 1.50 & 0.011 & 0.985 & 0.605 & 0.85 & 0.057 & 0.77 & 0.999 & 0.205 & 1.03 & 60.4 & 0.028 & 0.999 & 0.195 \\
\hline 0.80 & 1.75 & 0.015 & 0.977 & 0.976 & 0.68 & 0.103 & 0.72 & 0.997 & 0.395 & 1.00 & 42.7 & 0.025 & 0.997 & 0.429 \\
\hline 0.93 & 2.39 & 0.023 & 0.969 & 1.757 & 0.33 & 0.221 & 0.67 & 0.998 & 0.474 & 0.94 & 24.9 & 0.019 & 0.999 & 0.160 \\
\hline \multicolumn{15}{|c|}{ Gambe clay mud treated with locust bean gum } \\
\hline 0.13 & 0.29 & 0.004 & 0.953 & 0.382 & 0.00 & 0.039 & 0.67 & 0.995 & 0.120 & 0.00 & 127 & 0.123 & 0.996 & 0.106 \\
\hline 0.27 & 0.50 & 0.005 & 0.968 & 0.297 & 0.05 & 0.048 & 0.68 & 0.997 & 0.130 & 0.18 & 111 & 0.083 & 0.999 & 0.061 \\
\hline 0.40 & 0.78 & 0.009 & 0.992 & 0.588 & 0.23 & 0.05 & 0.75 & 0.993 & 0.356 & 0.35 & 72.9 & 0.041 & 0.994 & 0.253 \\
\hline 0.53 & 0.85 & 0.013 & 0.985 & 0.712 & 0.30 & 0.046 & 0.82 & 0.992 & 0.555 & 0.39 & 53.9 & 0.020 & 0.993 & 0.453 \\
\hline 0.67 & 1.92 & 0.017 & 0.961 & 1.484 & 0.99 & 0.225 & 0.63 & 0.999 & 0.226 & 0.67 & 30.6 & 0.027 & 0.999 & 0.108 \\
\hline 0.80 & 3.20 & 0.019 & 0.916 & 2.472 & 0.00 & 0.583 & 0.52 & 0.998 & 0.225 & 1.03 & 19.7 & 0.032 & 0.992 & 0.689 \\
\hline 0.93 & 5.29 & 0.030 & 0.905 & 4.160 & 0.00 & 1.021 & 0.50 & 0.997 & 0.784 & 1.59 & 11.6 & 0.021 & 0.991 & 1.141 \\
\hline
\end{tabular}




\begin{tabular}{|c|c|c|c|c|c|c|c|c|c|c|c|c|c|c|}
\hline \multirow{3}{*}{$\begin{array}{c}\text { Polymer } \\
(\%)\end{array}$} & \multicolumn{3}{|c|}{ Bingham Plastic Model Eq. } & \multicolumn{6}{|c|}{ Herschel-Bulkley Model Eq. } & \multicolumn{5}{|c|}{ Hyperbolic Model Eq. } \\
\hline & $\tau_{o 1}$ & $\mu_{p}$ & $\mathbf{R}^{2}$ & RMSE & $\tau_{o 2}$ & $k$ & $n$ & $\mathbf{R}^{2}$ & RSME & $\tau_{o 3}$ & $\boldsymbol{A}$ & $D$ & $\mathbf{R}^{2}$ & RSME \\
\hline & (Pa) & (Pa.s) & & & (Pa) & $\left(\mathbf{P a} . \mathbf{s}^{\mathrm{n}}\right)$ & & & & (Pa) & $(\text { Pa.s })^{-1}$ & $(\mathbf{P a})^{-1}$ & & \\
\hline \multicolumn{15}{|c|}{ Gambe clay mud treated with xanthan gum } \\
\hline 0.13 & 1.18 & 0.005 & 0.994 & 0.156 & 1.10 & 0.008 & 0.92 & 0.996 & 0.158 & 1.13 & 186 & 0.019 & 0.992 & 0.165 \\
\hline 0.27 & 2.74 & 0.008 & 0.954 & 0.789 & 1.88 & 0.101 & 0.64 & 0.989 & 0.454 & 2.17 & 65.1 & 0.054 & 0.988 & 0.467 \\
\hline 0.40 & 4.27 & 0.012 & 0.959 & 1.039 & 2.98 & 0.160 & 0.63 & 0.997 & 0.324 & 3.45 & 45.7 & 0.040 & 0.995 & 0.409 \\
\hline 0.53 & 5.82 & 0.014 & 0.920 & 1.773 & 3.51 & 0.388 & 0.53 & 0.980 & 1.026 & 4.53 & 31.9 & 0.039 & 0.975 & 1.152 \\
\hline 0.67 & 7.68 & 0.017 & 0.921 & 2.136 & 4.43 & 0.617 & 0.49 & 0.994 & 0.680 & 5.92 & 23.9 & 0.035 & 0.987 & 0.987 \\
\hline 0.80 & 11.95 & 0.016 & 0.910 & 2.152 & 9.39 & 0.422 & 0.53 & 0.966 & 1.547 & 10.58 & 29.4 & 0.033 & 0.956 & 1.743 \\
\hline 0.93 & 11.93 & 0.022 & 0.945 & 2.294 & 8.85 & 0.444 & 0.57 & 0.998 & 0.494 & 10.00 & 21.06 & 0.024 & 0.998 & 0.508 \\
\hline
\end{tabular}

James, O. O.; M. A., Mesubi, F. A., Adekola, E. O., Odenunmi, and J. I. D. Adekrye, (2008). Beneficiation and characterisation of a bentonite from northeastern Nigeria. Journal of the North Carolina Academy of Science, 124 (4): 154-1 58.

Joint Committee on Powder Diffraction Standards, (1980). Mineral powder diffraction file. vols. 1\&2. International Centre for Diffraction Data National Bureau of Standards, Washington DC.

Kelessidis, V. C., M., Zografou, and V. Chatzistamou (2013). Optimization of drilling fluid rheological and fluid loss properties utilizing PHPA polymer. Soc. Pet. Eng.

Maier, H., M., Anderson, C. Karl, and K. Magmuson (1993). Guar, locust bean, tara, and fenugreek gums. In: R. L. Whisiler and J. N. BeMiller (Eds), Industrial gums: polysaccharides and their derivatives. San Diego: Academic Press.

Mathur, N. K. (2012). Industrial Galactomannan Polysaccharides. CRC Press, Boca Raton.
Olatunde, A. O.; M. A., Usman, O. A., Olafadehan, T. A. Adeosun, and O. E. Ufot (2012). Improvement of rheological properties of drilling fluid using locally based materials. Petroleum \& Coal. 54 (1) pp. 65-75.

Otterstedt, J. and Brandreth, D. (1998). Small particles technology. 1st ed.Plenum Press, New York.

Shuwa, S. M. (2010). Beneficiation and evaluation of the potentials of Dikwa bentonitic clay for oil well drilling fluids formulation. MSc Thesis. Department of Chemical Engineering, Ahmadu Bello University, Zaria.

Ukeles, S. and Grinbaum, B. (2004). Drilling Fluids. In: Kirk-Othmer Encyclopedia of Chemical Technology (5th ed.).John Wiley \& Sons, Israel.

Wüstenberg, T. (2015). Cellulose and cellulose derivatives in the food industry: fundamentals and applications. Wiley, Weinheim, Germany.

Vipulanandan, C. and Mohammed, A. S. (2014). Hyperbolic rheological model with shear stress limit for acrylamide polymer modified bentonite drilling muds. Journal of Petroleum Science and Engineering, 122: 38-47. 